\title{
Peroral antegrade pancreatoscopy for pancreaticolithiasis after endoscopic ultrasound-guided recanalization of a complete pancreaticojejunal stenosis
}

Pancreaticoduodenectomy may result in symptomatic pancreaticojejunal stenosis in $2 \%-10 \%$ of cases [1]. As an alternative to surgery, endoscopic pancreatic duct decompression may be performed by retrograde (enteroscopy) or antegrade (endoscopic ultrasound [EUS]-guided transgastric access) approach [2]. The latter is more likely to be technically successful (up to $70 \%$ of cases) [3], and also enables anastomotic recanalization [4]. For pancreaticolithiasis treatment, an antegrade pancreatoscopy procedure has been recently described as feasible and useful [5].

We herein describe the case of a 51-yearold woman who presented with abdominal pain and several episodes of mild pancreatitis in the preceding 12 months. Symptoms were due to a pancreaticojejunal stenosis and obstructing pancreatic ductal stones following a curative pancreaticoduodenectomy performed 8 years earlier (\$ Fig.1). After a previous EUS-guided attempt failed because of complete pancreaticojejunal stenosis, a successful EUS-guided pancreatic recanalization was achieved in June 2017, which enabled the placement of a transgastric indwelling double-pigtail stent across the stenosis ( Fig.2, $>$ Fig. 3 , $\checkmark$ Video 1). The patient became asymptomatic.

In March 2018, it was decided to perform a peroral transgastric pancreatoscopy to evaluate a persistent pancreaticojejunal stenosis and treat any remaining ductal stones. After stent removal and endoscopic dilation of the stenosis and gastric tract ( $\triangleright$ Fig.4), a digital single-operator peroral cholangioscope (SpyGlass DS, Boston Scientific, Marlborough, Massachusetts, USA) was inserted through a standard therapeutic duodenoscope into the pancreatic duct until it reached

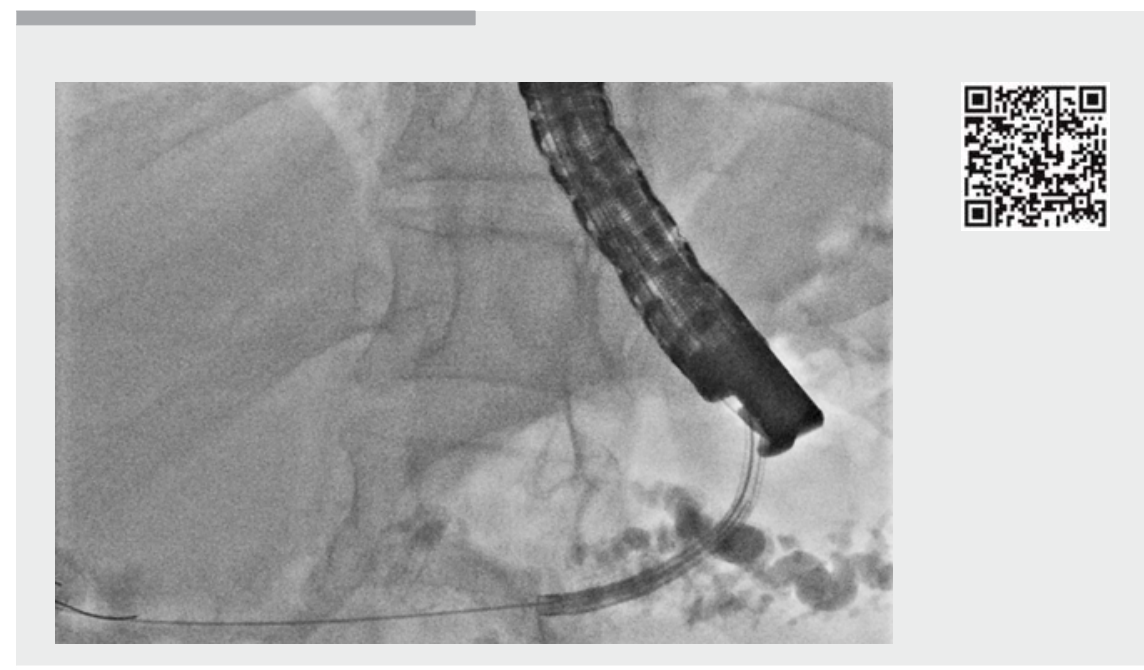

$\checkmark$ Video 1 Peroral antegrade pancreatoscopy for evaluating and treating pancreaticojejunal stenosis and pancreatic ductal stone.

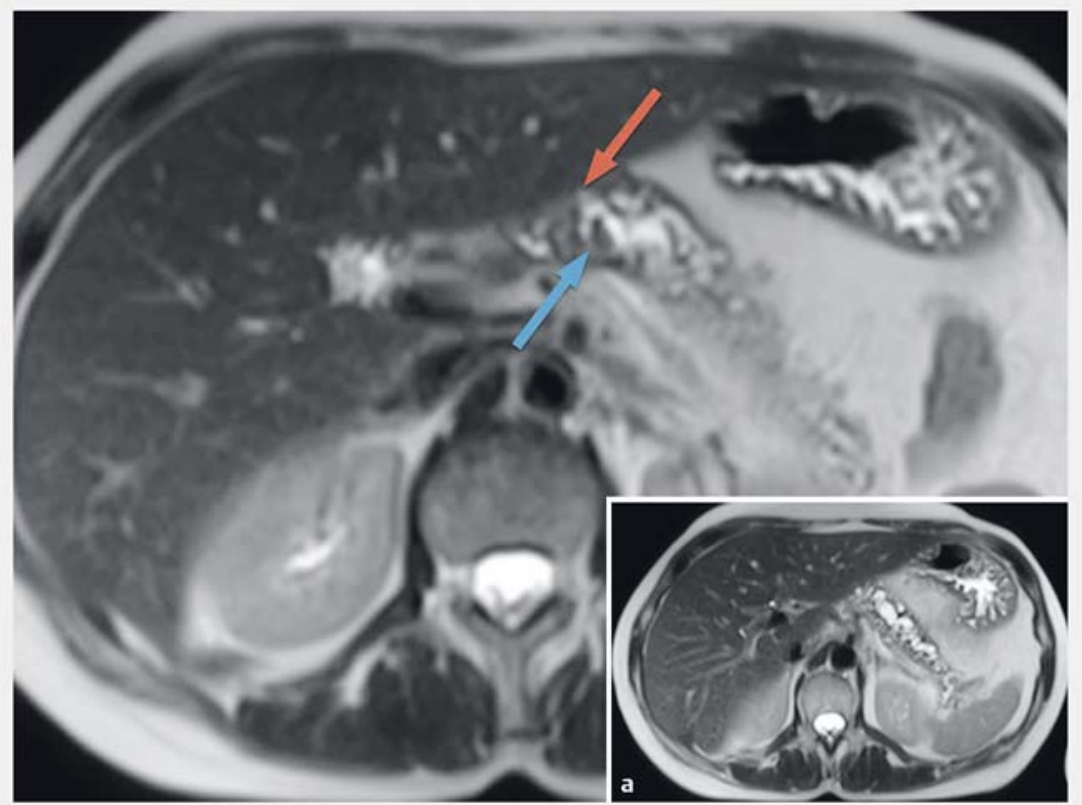

- Fig. 1 A complete pancreaticojejunal stenosis (red arrow) and pancreatic ductal stone (blue arrow) was seen on magnetic resonance cholangiopancreatography, with a dilated mid-distal pancreatic duct (a). 


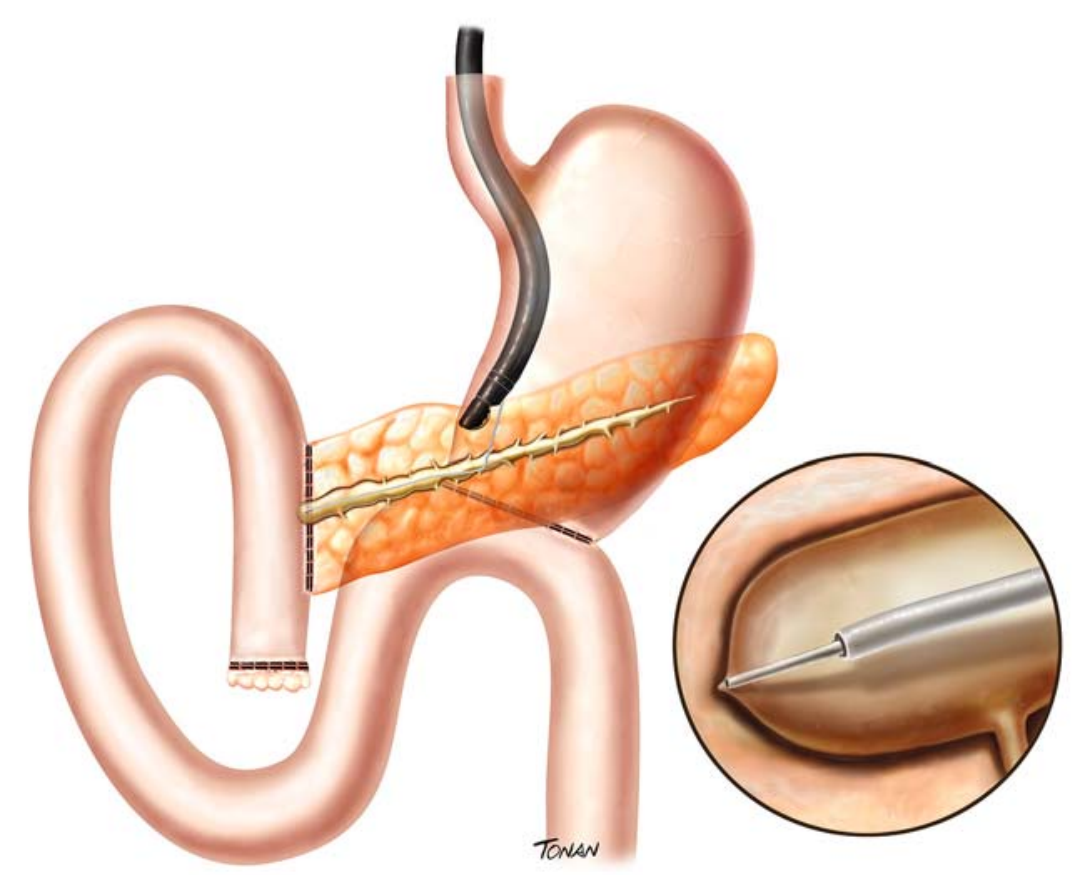

- Fig.2 An electrocautery needle-knife was inserted inside the pancreatic duct in order to traverse the pancreaticojejunal stenosis for jejunal access. Source: Rodrigo Ricieri Tonan.

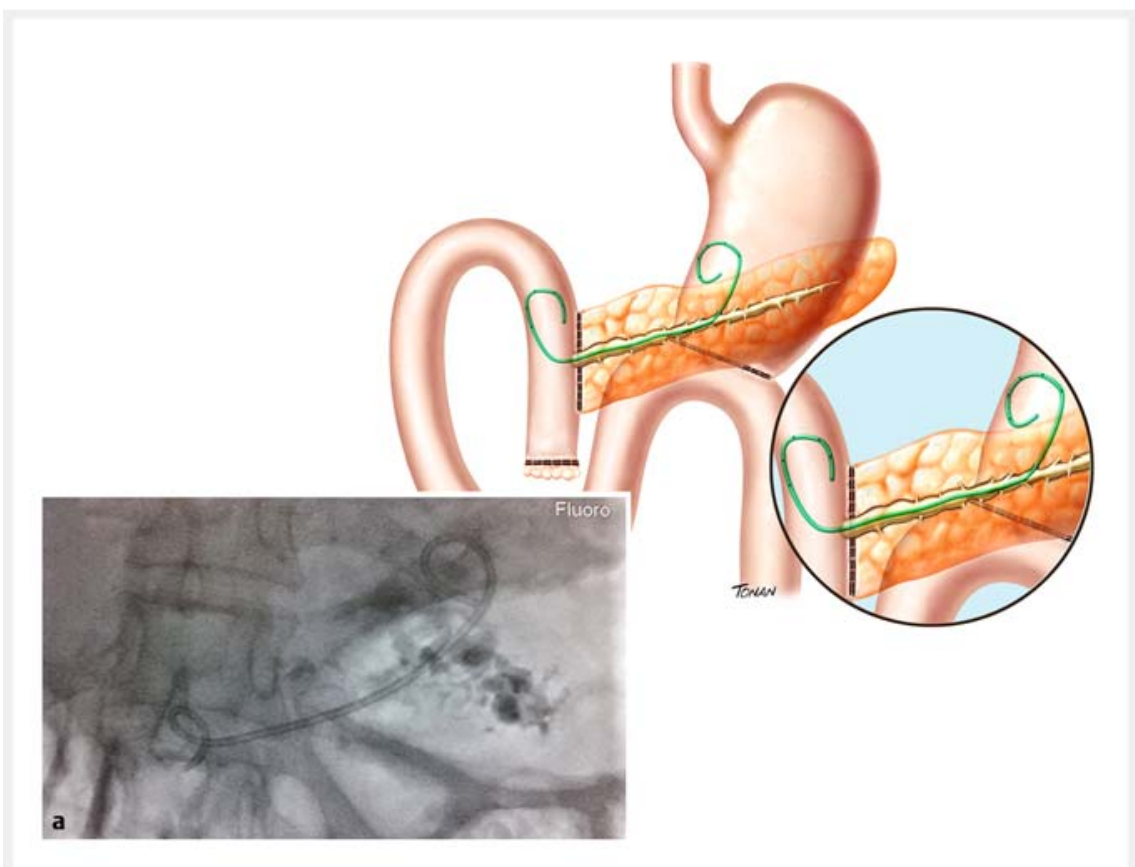

- Fig. 3 A transgastric indwelling double-pigtail stent was placed across the stenosis, with fluoroscopic view (a). Source: Rodrigo Ricieri Tonan.

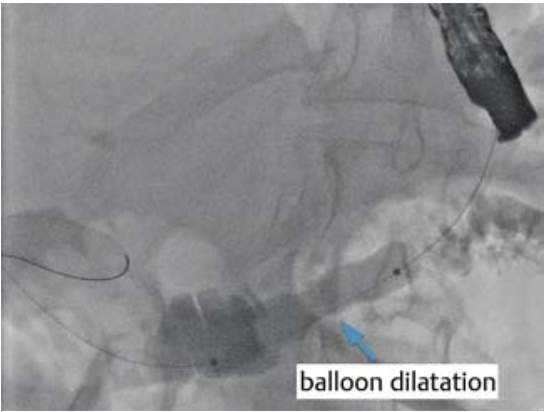

- Fig. 4 Endoscopic balloon dilation of the pancreatic stenosis using a $15 \mathrm{~mm}$ hydrostatic balloon.

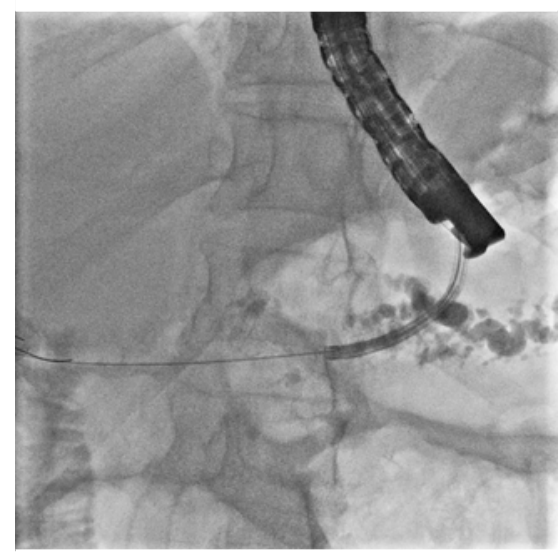

- Fig. 5 A peroral cholangioscope was inserted inside the pancreatic duct through the gastric tract.

the jejunum ( $\triangleright$ Fig.5, $>$ Video 1 ). This revealed a fibrotic pancreaticojejunal stenosis, $3 \mathrm{~cm}$ in length, and a persistent pancreatic ductal stone, $4 \mathrm{~mm}$ in size (ฉ Fig.6). Pancreatic ductal clearance was achieved using water irrigation and push-and-pull maneuver, with no need for intraductal lithotripsy. A $10 \mathrm{Fr} 12 \mathrm{~cm}$ transgastric plastic biliary stent was placed across the stenosis.

The patient was discharged the day after the procedure and continued to do well 60 days later. This patient will need further stent replacement until a desirable and stable pancreaticojejunal opening is achieved.

Endoscopy_UCTN_Code_TTT_1AR_2AB 


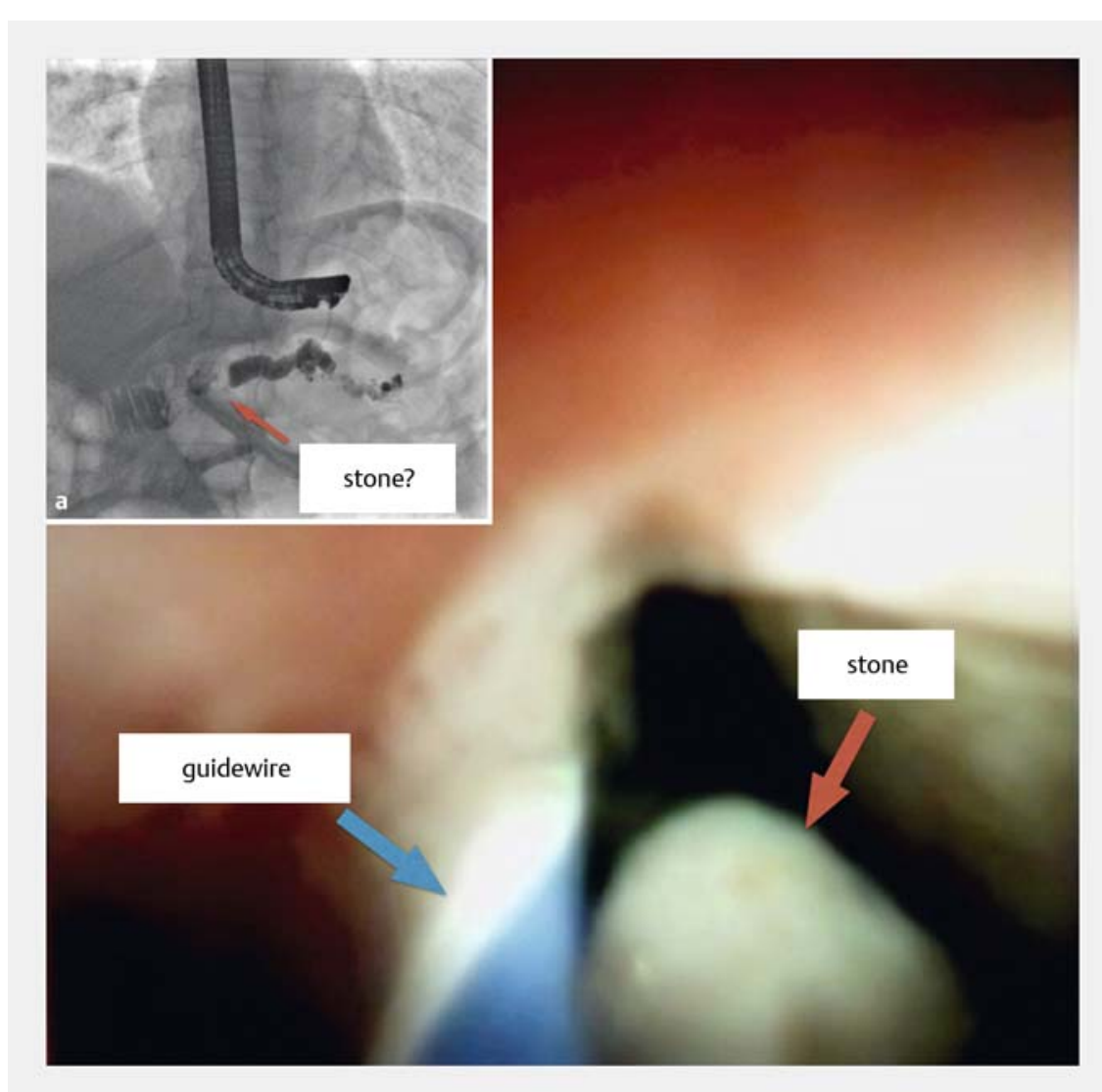

- Fig. 6 Pancreatoscopy confirmed a persistent $4 \mathrm{~mm}$ pancreatic ductal stone (red arrow), which was suspected at pancreatography (a). A guidewire can be seen in the pancreatic duct (blue arrow).

\section{Acknowledgments}

The authors are grateful to the Digestive Endoscopy and Interventional Radiology team unit of Hospital de Clínicas da Universidade Federal do Paraná. The authors also thank Drs. Camila Travensoli Bobato and Bruna Cristina Opolski for helping care for the patient, and the Boston Scientific team from Curitiba for technical support.

\section{Competing interests}

None

\section{References}

[1] Demirjian AN, Kent TS, Callery MP, Vollmer $\mathrm{CM}$. The inconsistent nature of symptomatic pancreatico-jejunostomy anastomotic strictures. HPB (Oxford) 2010; 12: 482 - 487

[2] Chen Yl, Levy M], Moreels TG et al. An international multicenter study comparing EUSguided pancreatic duct drainage with enteroscopy-assisted endoscopic retrograde pancreatography after Whipple surgery. Gastrointest Endosc 2017; 85: 170 - 177

[3] Fujii LL, Topazian MD, Abu Dayyeh KB et al. EUS-guided pancreatic duct intervention: outcomes of a single tertiary-care referral center experience. Gastrointest Endosc 2013; 78: 854 -864.e1

[4] Ryou M, Mullady DK, Dimaio CJ et al. Pancreatic antegrade needle-knife (PANK) for treatment of symptomatic pancreatic duct obstruction in Whipple patients (with video). Gastrointest Endosc 2010; 72: 1081 1088

[5] James TW, Baron TH. Antegrade pancreatoscopy via EUS-guided pancreaticogastrostomy allows removal of obstructive pancreatic duct stones. Endosc Int Open 2018; 6: E735-E738

\section{Bibliography}

DOI https://doi.org/10.1055/a-0677-1623

Published online: 10.9.2018

Endoscopy 2018; 50: E333-E335

(c) Georg Thieme Verlag KG

Stuttgart · New York

ISSN 0013-726X

\section{ENDOSCOPY E-VIDEOS \\ https://eref.thieme.de/e-videos}

\section{de Souza ${ }^{1}$, Eloy Taglieri ${ }^{2}$, Nelson Silveira}

Cathcart ${ }^{1}$, Elisandre Caroline dos Santos ${ }^{1}$, Ricardo Schmitt de Bem ${ }^{1}$, José Celso Ardengh ${ }^{2}$

1 Endoscopy Unit, Hospital de Clínicas Universidade Federal do Paraná, Curitiba, Brazil

2 Endoscopy Unit, Hospital Nove de Julho, São Paulo, Brazil

\section{Corresponding author}

\section{Eduardo Aimore Bonin, MD}

Endoscopy Unit, Hospital de Clínicas Universidade Federal do Paraná, Rua Petit Carneiro, 1111, CEP 80240050 Curitiba, Parana, Brazil Fax: +55-41-33601800 eabonin@gmail.com freely accessible online.

This section has its own submission website at https://mc.manuscriptcentral.com/e-videos 